\title{
The Appropriate Approach for Statics and Dynamics in Engineering Technology
}

\author{
David Myszka \\ Mechanical Engineering Technology \\ University of Dayton
}

\begin{abstract}
Engineering mechanics, specifically statics and dynamics, is a critical foundation for advanced topics in several technical disciplines. On the surface, the common, application oriented focus of engineering technology would suggest a common approach to these fundamental topics. However, there is a large variation in the curricular format and pedagogy used to introduce mechanics among engineering technology programs across the country.
\end{abstract}

A study was conducted to identify the different approaches used in mechanics courses in different engineering technology programs. Additionally, a study that distinguishe s the factors of success in the engineering mechanics courses at the University of Dayton will be reviewed. Using these studies, recommendations for an ideal approach will be suggested.

\section{Introduction}

Statics and Dynamics is the first course, or courses, in a series commonly referred to as engineering mechanics. It is a fundamental prerequisite for subsequent courses such as strength of materials and kinematics. Further, performance in these latter courses can be directly correlated to success in Statics. ${ }^{4}$

Since understanding Statics and Dynamics is crucial to the future work of technical professionals, Concept Inventory projects have been sponsored by the National Science Foundation ${ }^{5,10,11}$. These studies identify the concepts and skills essential for understanding and application of engineering mechanics.

Also, in the past few years, many innovative pedagogical techniques for guiding students through engineering mechanics have been documented ${ }^{6,7,15,16}$. The primary focus of these studies has been with engineering programs. Yet, a common assumption is that these techniques can also be implemented in engineering technology programs. While this is true for many methods, some important differences exist.

The traditional method of teaching Statics and Dynamics to engineering technology students is without using vector notation. A popular belief is that students are better able to apply the concepts of mechanics without the elaborate mathematics procedures required for vector notation. In fact, many instructors feel that the mathematical sophistication detracts from understanding the core concepts. 


\section{Available Instructional Materials}

Textbooks and other teaching materials for engineering mechanics can be separated into four categories:

1. Elementary books that are primarily intended for vocational and two-year programs. Topics are presented in a preliminary nature and worked examples and practice problems are at a rather low-level. Examples include "Applied Mechanics for Engineering Technology" by Keith Walker (7/e, Prentice Hall, $2004)^{17}$, “Technical Mechanics" by Irving Granet (1/e, HRW, 1983) ${ }^{9}$ and "Introduction to Mechanics" by Irving Levingston (2/e, Prentice Hall, 1968) ${ }^{14}$.

2. Books that offer a thorough presentation of engineering mechanics theory and application. These books utilize vector notation, using the related mathematical methods. The y are tailored for theoretical engineering programs, and have a large market. Accordingly, many textbooks with this focus are available. The most popular are "Engineering Mechanics: Statics and Dynamics" by Russell Hibbeler (10/e, Prentice Hall, 2003) 12 , and "Vector Mechanics for Engineers: Statics and Dynamics" by Ferdinand Beer and E. Russell Johnston (6/e, McGraw-Hill, $2000)^{2}$.

3. Books that present mechanics topics with significant depth and rigor using algebraic and trigonometric analysis techniques. Traditionally these textbooks have been used in applied engineering programs and baccalaureate engineering technology programs. The most popular texts have been written by authors of books vector notation, but presented without the mathematical complexity. Since the market, and sales numbers, are not as large as their theoretical counterparts, less attention is paid to these versions. Consequently, they are not updated frequently and are in danger of becoming out-of-print. Example s include "Mechanics for Engineers: Statics and Dynamics" by Russell Hibbeler (4/e, Macmillan, 1985 $)^{13}$, "Mechanics for Engineers: Statics and Dynamics" by Ferdinand Beer and E. Russell Johnston (4/e, McGraw-Hill, 1987) ${ }^{3}$.

4. Multimedia materials that allow guided instruction, interactive example problems and practice problem. The potential for these materials appears enormous. Yet, the effort to develop these materials also is enormous. To date, it does not appear that any institution has adopted these materials as the primary teaching instrument. Examples include "Multimedia Engineering Statics and Dynamics" by Kurt Gramoll (CD-ROM, Addison-Wesley, 1997) ${ }^{8}$ and "Engineering Mechanics Study Pack" by Anthony Bedford and Wallace Fowler (3e, Prentice Hall, 2002) ${ }^{1}$

\section{Approach used for Mechanics in Selected Engineering Technology Programs}

A focus group study of 13 selected ABET accredited, baccalaureate engineering technology programs was conducted. This study reviewed the curricular aspects of engineering mechanics (statics and dynamics) and college physics. The universities

"Proceedings of the 2005 American Society for Engineering Education Annual Conference \& Exposition Copyright (C) 2005, American Society for Engineering Education” 
involved in the study included: The University of Dayton, University of Cincinnati, Arizona State University - East, Indiana University/Purdue University at Indianapolis, Purdue University, Penn State - Erie, Michigan Technological University, Wayne State University, Kansas State University - Salina, Ferris State University, Old Dominion University, Milwaukee School of Engineering, and Rochester Institute of Technology.

The following observations were made:

- $62 \%$ of the mechanical engineering technology programs require a dedicated statics course.

- $23 \%$ of the mechanical engineering technology programs require a combined course to introduce static s with strength of materials.

- $15 \%$ of the mechanical engineering technology programs require a combined course to introduce statics with dynamics.

- $33 \%$ of the mechanical engineering technology programs use vector notation $(\mathrm{i}, \mathrm{j}, \mathrm{k})$ and analysis in the static s course.

- $54 \%$ of the programs require a non-calculus, College Physics I course (physics of mechanics) as a prerequisite for a statics course.

- Of the 13 institutions, 9 different text books are used in the statics (or combination) course.

- $100 \%$ of the mechanical engineering technology programs require a course (or combined course) in dynamics.

- $46 \%$ of the mechanical engineering technology programs require the dynamics (or combined) course as a prerequisite for a course in kinematics.

- $31 \%$ of the mechanical engineering technology programs require dynamics as a prerequisite for a machine design course.

- $7 \%$ (1) mechanical engineering technology program uses dynamics as a prerequisite for fluid mechanics

- $15 \%$ of the mechanical engineering technology programs require a course in kinematics without using dynamics as a prerequisite.

- $38 \%$ of the mechanical engineering technology programs do not require a separate course in kinematics.

- $23 \%$ of the mechanical engineering technology programs do not use dynamics a prerequisite course for other required courses.

- Of the 13 institutions, 6 different text books are used in the dynamics course.

\section{Mechanics Sequence at the University of Dayton}

All engineering technology programs (Computer, Electronic, Industrial, Manufacturing and Mechanical) at the University of Dayton require a combined introductory engineering mechanics course; MCT 220: Statics and Dynamics. The distribution of topics in this three-semester hour course is roughly $75 \%$ statics and $25 \%$ dynamics. It uses a basic calculus course as a prerequisite. At this time, vector notation is not used. The textbook is engineering Mechanics: Statics and Dynamics, by Beer and Johnston ${ }^{4}$. 
Statics and Dynamics serves as a prerequisite for a kinematics/mechanisms course and subsequently a machine dynamics course. Additionally, Statics and Dynamics serve as a prerequisite for a strength of materials course and subsequently a machine design course.

All students are also required to take an algebra based physics course; PHY 201: College Physics I. This physics course does not serve as a prerequisite for the engineering mechanics course.

The required mechanics sequence for mechanical engineering technology students at the University of Dayton is presented graphically in figure 1.

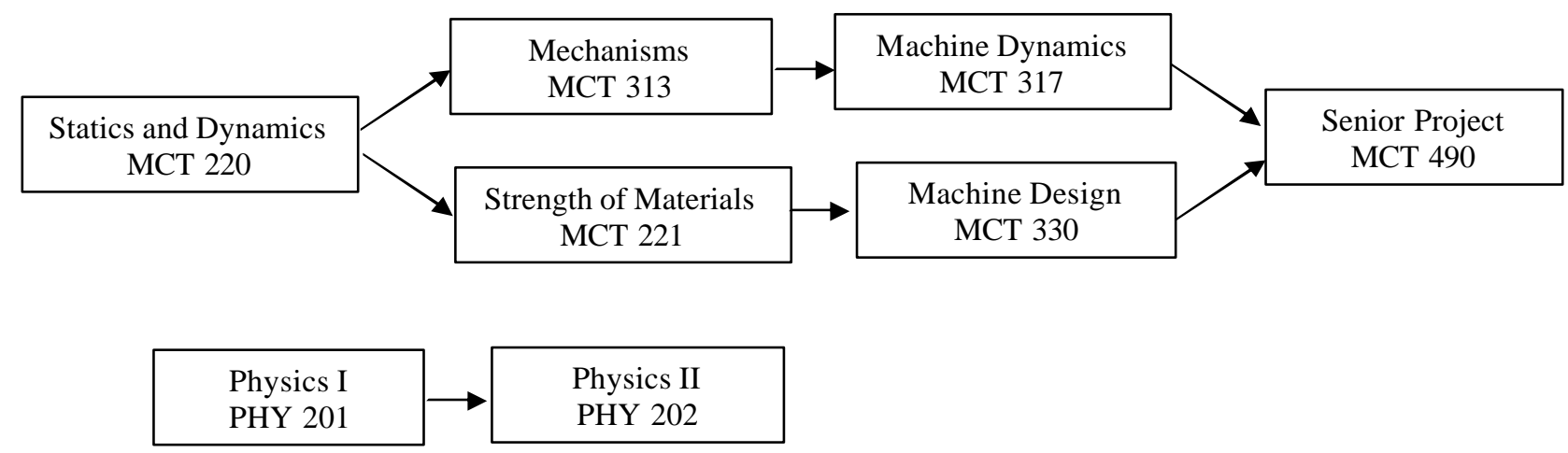

Figure 1

\section{Performance in Mechanics at the University of Dayton}

A study was conducted at the University of Dayton to assess the performance of engineering technology students in the basic mechanics. Specifically monitored was the performance in two courses:

- The algebra-based, physics of mechanics course (PHY 201)

- The combined, statics and dynamics course using traditional algebraic notation. (MCT 220)

The study group consisted of 125 students, all who took either course between 1999 and 2004. No distinction was made between instructors, and course assessment tools. Only final course grades were reviewed. This sample should be fairly typical of students in most ABET accredited, baccalaureate engineering technology programs.

\section{Performance in College Physics}

The average grade of students in PHY 201 was 2.76 (B-). Many factors and relationships that affected performance were reviewed. The strongest correlation detected was the physics grade with the performance in standardized tests. Thus, the "most intelligent" students did best in physics. This data is shown in table 1 . 


\begin{tabular}{|c|c|c|c|}
\hline Grade in PHY201 & Average SAT & Average ACT & Overall GPA \\
\hline A, or A- & 1095.0 & 25.0 & 3.23 \\
\hline B+, B, or B- & 1084.7 & 22.8 & 3.00 \\
\hline C+, C, or C- & 1072.6 & 23.1 & 2.77 \\
\hline D & 1034.7 & 22.6 & 2.28 \\
\hline F & 1040.0 & 22.3 & 1.92 \\
\hline
\end{tabular}

Table 1

Timing of the College Physics Course

The performance in the physics course was observed relative to the semester taken. The rationale behind this study was to determine whether maturation and college experience assists performance. However, this notion did not appear to be valid. While a clear trend is not evident, overall first year students performed better. Table 2 illustrates this data $(1 \mathrm{~A}=$ first year, first semester; $2 \mathrm{C}=$ second year, third semester; etc. $)$

\begin{tabular}{|c|c|c|c|}
\hline Semester & Students & \multicolumn{2}{|c|}{ Average Grade } \\
\hline 1A & 28 & 2.40 \\
\hline 1B & 9 & 1.88 \\
\hline 1C & 5 & 2.80 & \\
& 2.33 \\
\hline 2A & 21 & 1.71 \\
\hline 2B & 1 & 1.00 & \\
\hline 2C & 12 & 2.66 & \\
\hline 3A & 18 & 2.24 & \\
\hline 3C & 2 & 2.33 & \multirow{2}{*}{2.24} \\
\hline 4A & 1 & 1.66 & 1.66 \\
\hline
\end{tabular}

Table 2

\section{Mathematics preparation for the College Physics Course}

The prerequisite for PHY 201 is high school algebra and trigonometry. Yet, the performance was observed relative to the level of college mathematics completed before beginning the physics course. The rationale behind this observation was to determine whether advance knowledge in mathematics assists performance. However, as can be induced from the previous observation, no relationship between college experience in mathematics and performance in physics was detected.

\section{Performance in the College Physics Course based on Degree Program}

All engineering technology majors are required to complete PHY 201. Of course, it most directly relates to the mechanical program, and it was assumed that the interest level is greater for these students. The data revealed that students majoring in Computer Engineering Technology had the best performance in the physics of mechanics course. The data is shown in table 3. This once again points to "intelligence", and not interest, being the primary indicator of performance in physics. 


\begin{tabular}{|l|c|c|}
\hline Academic Major & $\begin{array}{c}\text { Average } \\
\text { Physics Grade }\end{array}$ & $\begin{array}{c}\text { No. of Students in } \\
\text { the Study }\end{array}$ \\
\hline Computer ET & 2.47 & 10 \\
\hline Electronic ET & 2.37 & 9 \\
\hline Mechanical ET & 2.22 & 52 \\
\hline Industrial ET & 1.95 & 24 \\
\hline Manufacturing ET & 1.85 & 8 \\
\hline
\end{tabular}

Table 3

\section{Performance in Statics and Dynamics}

The average grade of students in MCT 220 was 2.89 (B-). Similar to physics, a strong correlation of student grades in engineering mechanics to their overall grade point average was observed. Unlike physics, a strong correlation to performance in standardized tests was not as evident. Thus, the most academically successful students were also successful in engineering mechanics. It is believed that academic success, and performance in engineering mechanics, is a combination of intelligence and work ethic. This data is shown in table 4 .

\begin{tabular}{|c|c|c|c|}
\hline Grade in MCT220 & Average SAT & Average ACT & Overall GPA \\
\hline A, or A- & 1122.2 & 23.8 & 3.43 \\
\hline B+, B, or B- & 1043.8 & 23.3 & 3.01 \\
\hline C+, C, or C- & 1125.5 & 23.5 & 2.86 \\
\hline D & 1058.8 & 22.7 & 2.51 \\
\hline F & 1060.0 & 21.3 & 1.95 \\
\hline
\end{tabular}

Table 4

Timing of the Statics and Dynamics Course

The performance in the engineering mechanics course was observed relative to the semester taken. As with physics, the rationale behind this study was to determine whether maturation and college experience assists performance. Very few students took engineering mechanics in the first year, and it is assumed that these were advanced students. On average, juniors did better than sophomores. Table 5 illustrates this data (1B $=$ first year, second semester; $2 \mathrm{~A}=$ second year, first semester; etc.)

\begin{tabular}{|c|c|c|c|}
\hline Semester & Students & \multicolumn{2}{|c|}{ Average Grade } \\
\hline 1B & 3 & 3.00 & 3.00 \\
\hline 2A & 43 & 2.09 & \\
& \multirow{2}{*}{2.14} \\
\hline 2B & 20 & 2.05 & \multirow{2}{*}{2.14} \\
\hline 3A & 6 & 2.84 & \\
\hline 3B & 7 & 2.28 & \multirow{2}{*}{2.37} \\
\hline
\end{tabular}

Table 5 
Performance in Statics and Dynamics based on Degree Program

All engineering technology majors are required to complete MCT 220. As with physics, the topics most directly relate to the mechanical program, and it was assumed that the interest level is greater for these students. The data revealed that the electronic and computer students had the best performance in college physics of mechanics. The data is shown in table 6 . This once again points to intelligence and work ethic, and not interest, being the primary indicator of performance in engineering mechanics.

\begin{tabular}{|l|c|c|}
\hline Academic Major & $\begin{array}{c}\text { Average } \\
\text { Mechanics Grade }\end{array}$ & $\begin{array}{c}\text { No. of Students in } \\
\text { the Study }\end{array}$ \\
\hline Electronic ET & 2.60 & 20 \\
\hline Computer ET & 2.30 & 17 \\
\hline Mechanical ET & 2.25 & 44 \\
\hline Manufacturing ET & 2.00 & 11 \\
\hline Industrial ET & 1.89 & 31 \\
\hline
\end{tabular}

Table 6

Performance in Statics and Dynamics after completing College Physics

The performance in engineering mechanics was not affected by completing the physics course. The average was not significantly different for those completing physics prior, at the same time, or after engineering mechanics. This contradicts the popular theory that physics serves as a valuable prerequisite for engineering mechanics.

\section{Performance in College Physics after completing Statics and Dynamics}

The performance in physics was affected by completing the engineering mechanics course. For those students who took physics after the engineering mechanics course, 67\% did the same or better in PHY 201 than they did in MCT 220.This gives rise to an unconventional proposal of having engineering mechanics serve as a prerequisite for college physics.

\section{Conclusions and Recommendations}

After reviewing the results of these two studies, and associated comments from the focus group participants, the following recommendations can be made:

- Statics and dynamics textbooks, written for theoretical, engineering programs can be successfully used in engineering technology programs. Several programs adopt these books, yet utilize varied amounts of the mathematical complexity. However, consistent with the mission of engineering technology education, applications of the analysis on machinery and structures, and not the mathematical developments, should be emphasized. 
- All focus group participants with combined courses (Statics/Dynamics, or Statics/Strength of Materials) complain about a lack of sufficient time. This suggests that is best to have separate statics and dynamics courses.

- The performance in engineering mechanics best correlates with intelligence, which is a primary contributor to GPA. Thus, pedagogy used in traditional mechanics courses could be improved to engage all students. It is recommended that instructors in mechanics courses seriously review the latest techniques that better address lower performing students with remedial work ${ }^{6,7,15,16}$.

- Topical interest is not a significant factor for performance in engineering mechanics, since computer/electronic students perform better than mechanical students. Therefore, more effort should be placed in emphasizing the applicability of the topics to machines and structures, which may engage students who will benefit most from a sound understanding of mechanics.

- Since completing a physics course does not affect the performance in engineering mechanics, using physics as a prerequisite is not warranted.

While these recommendations are not strictly based on the statistical information, they do originate from careful observations of performance at the University of Dayton and at a variety of other institutions.

\section{References}

1. Bedford, A., Fowler, W., Engineering Mechanics Study Pack, Prentice Hall, $3^{\text {rd }}$ Edition, 2002.

2. Beer, F., Johnston, E., Engineering Mechanics: Statics and Dynamics, McGraw Hill, $6^{\text {th }}$ Edition, 2000.

3. Beer, F., Johnston, E., Mechanics for Engineers: Statics and Dynamics, Mc Graw Hill, $4^{\text {th }}$ Edition, 1987.

4. Danielson, S. G., and Danielson, E. B. "Problem Solving: Improving a Critical Component of Engineering Education", Annual Conference of the American Society for Engineering Education, Toledo, OH, 1992.

5. Danielson S., "Knowledge Assessment in Statics: Concept versus Skills", Annual Conference of the American Society for Engineering Education, Salt lake City, UT, 2004.

6. Dollar, A., and Steif, P., Reinventing the Teaching of Statics, Annual Conference of the American Society for Engineering Education, 2004.

7. Dollar, A., and Steif, P., Learning Modules for the Statics Classroom, Annual Conference of the American Society for Engineering Education, 2003.

8. Gramoll, K., Multimedia Engineering Statics and Dynamics, Addison Wesley, 1997.

9. Granet, I., Technical Mechanics: Applied Statics and Dynamics, Holt, Rinehart and Winston, $1^{\text {st }}$ Edition, 1983.

10. Gray, G., Evans, D., Cornwell, P., Costanzo, F., and Self, B., Towards a Nationwide Dynamics Concept Inventory Assessment Test, Annual Conference of the American Society for Engineering Education, 2004.

11. Hestenes, D., Wells, M., and Swackhamer, G., "Force Concept Inventory", The Physics Teacher, 30, 1992, pp. 141-158.

12. Hibbeler, R., Engineering Mechanics: Statics and Dynamics, Prentice Hall, $10^{\text {th }}$ Edition, 2003.

13. Hibbeler, R., Mechanics for Engineers: Statics and Dynamics, MacMillian, $4^{\text {th }}$ Edition, 1985.

14. Levingston, I., Introduction to Mechanics, Prentice Hall, $2^{\text {nd }}$ Edition, 1968.

15. Mariappan, J., Shih, A., and Schrader, P., Scenario-Based Learning Approach in Teaching Statics, Annual Conference of the American Society for Engineering Education, 2004.

"Proceedings of the 2005 American Society for Engineering Education Annual Conference \& Exposition Copyright (C) 2005, American Society for Engineering Education” 
16. Steif, P., and Dollar, A., New Approaches to Teaching and Learning Statics, Annual Conference of the American Society for Engineering Education, 2003.

17. Walker, K., Applied Mechanics for Engineering Technology, Prentice Hall, $7^{\text {th }}$ Edition, 2004.

\section{Biographical Information}

\section{DAVID MYSZKA}

Dave Myszka is a Professor of Engineering Technology at the University of Dayton. Dave is a Registered Professional Mechanical Engineer in Ohio and is actively involved in applied research with industry. Dave received a B.S. and M.S. degrees in Mechanical Engineering from the State University of New York at Buffalo in 1985 and 1989, respectively. He also received an M.B.A. degree from the University of Dayton in 1996. 